\title{
Tribological behavior of ammonium-based protic ionic liquid as lubricant additive
}

\author{
Hong GUO, Patricia IGLESIAS* \\ Mechanical Engineering Department, Rochester Institute of Technology, New York 14623-5603, USA \\ Received: 19 March 2019 / Revised: 11 June 2019 / Accepted: 28 February 2020 \\ (C) The author(s) 2020.
}

\begin{abstract}
In this study, the tribological behavior of an ammonium-based protic ionic liquid (PIL) as an additive in a base mineral oil (MO) is investigated on a steel-steel contact at room temperature and $100{ }^{\circ} \mathrm{C}$. Tri-[bis(2-hydroxyethylammonium)] citrate (DCi) was synthesized in a simple and low-cost way, and the ionic structure of DCi was confirmed by proton nuclear magnetic resonance ( ${ }^{1} \mathrm{H}$ NMR). The stability measurement of $1 \mathrm{wt} \%$ DCi to a MO was investigated, and the lubricating ability and anti-wear properties of DCi as an additive in $\mathrm{MO}$ were also examined using a custom-designed reciprocating ball-on-flat tribometer. Optical microscope and profilometry were used to obtain the worn morphology of the steel disks. Scanning electron microscopy (SEM) and energy dispersive X-ray spectroscopy (EDS) were carried out to investigate the wear mechanism and to analyze the surface interactions between the rubbing components. When $1 \mathrm{wt} \% \mathrm{DCi}$ is added into the base $\mathrm{MO}$, frictional performance is improved at both temperatures studied with a friction reduction of $29.0 \%$ and $35.5 \%$, respectively. Moreover, the addition of $1 \mathrm{wt} \%$ DCi to MO reduced the wear volume $59.4 \%$ compared to the use of MO. An oxygen-richened tribolayer is confirmed by EDS on the disk surface when DCi was used as additive under $100^{\circ} \mathrm{C}$.
\end{abstract}

Keywords: protic ionic liquid (PIL); tri-[bis(2-hydroxyethylammonium)] citrate (DCi); steel-steel; friction; wear

\section{Introduction}

It is estimated that the energy consumption from tribological contacts accounts for $23 \%$ which is around 119 EJ of the world's total energy consumption [1]. In order to reduce the energy losses and increase the energy efficiency of mechanical systems, one approach is to add additives, such as friction modifier additives or anti-wear additives, to the lubricant to obtain improved tribological performance [2]. Ionic liquids (ILs) have attracted attention of the research community as lubricants or lubricant additives since they been explored for lubrication in 2001 [3]. ILs are synthetic salts that consist of cations and anions with melting point below $100{ }^{\circ} \mathrm{C}$ or even lower. The most commonly used cations of ILs are ammonium [4, 5], imidazolium [6], pyridinium [7], or phosphonium [8, 9], where the anions could be either organic or inorganic [10]. ILs have a number of unique properties which make them outperform conventional lubricants or lubricant additives, such as high temperature stability, low flammability, negligible volatility as well as high thermal conductivity [3, 11, 12]. Oil-miscible ILs are explored and reported with promising anti-wear properties in early 2012 [13, 14], and since then, ILs used as lubricant additives have become a new topic.

Aprotic ionic liquids (APILs) are a subset of ILs, and have been widely studied for more than a decade and proved to have the potential to be lubricant and lubricant additives [15-19]. However, most of the APILs contain halogen elements such as fluorine or chlorine, which can easily form hydrofluoric or hydrochloric acid when exposed to the moisture atmosphere, and then corrode the metal workpieces. APILs are also

* Corresponding author: Patricia IGLESIAS, E-mail: pxieme@rit.edu 
very expensive because of their complicated synthesis route [20]. Protic ionic liquids (PILs), which are another subset of ILs, can be easily obtained by combination of a Brønsted acid and a Brønsted base. These PILs possess a wide range of properties, such as high viscosity, high thermal and electronic conductivity, non-flammability, and low toxicity [21]. These properties make PILs suitable in many areas such as catalyst [22, 23], nanostructured materials [24], and electrochemistry [25]. Ethylammonium nitrate $\left[\left(\mathrm{C}_{2} \mathrm{H}_{5} \mathrm{NH}_{3}\right) \mathrm{NO}_{3}\right]$ is found to be the first PIL at roomtemperature and reported by Walden in 1914 [26]. PILs can be tailored by changing cation structures, anion structures or both to satisfy specific requirements [22, 27-29]. Due to the easy synthetic route, low cost and toxicity, PILs can be a suitable alternative to APILs in lubrication.

When lubricants are used in the automotive industry, they are not only being used to protect the engine but also should be formulated to minimize the impact on the exhaust after treatment devices, such as catalytic converters or diesel particulate filters [30]. It is found that phosphorus oxides, sulfur oxides, and ash will reduce the effective life of exhaust catalysts, leading to the limitation of the level of phosphorus and sulfur in engine oils [31]. The development of more environmentally-friendly ILs that are free from halogens, sulfurs, and phosphorus is needed to satisfy the restrictive regulations [32].

In this work, a protic ammonium cation and carboxylate anion, with only carbons, hydrogens, nitrogen, and oxygens, will be used as a new PIL. The lubricating ability and anti-wear property of this ammonium-based PIL as additive to a commercially available mineral oil (MO) in steel-steel contact mode will be investigated using a ball-on-flat reciprocating tribometer.

\section{Materials and methods}

The base oil used in this study is a MO provided by Repsol (Spain), and its properties are summarized in Table 1. Diethanolamine $(\geq 98.0 \%)$ and citric acid ( $\geq 99.5 \%$ ) were purchased from Sigma Aldrich (USA). The PIL, tri-[bis(2-hydroxyethylammonium)] citrate (DCi), was synthesized in our laboratory through the following process [33]: $0.6 \mathrm{~mol}$ diethanolamine was dissolved in ethanol $(100 \mathrm{ml})$ to form a liquid solution, and shifted to a $500 \mathrm{ml}$ three neck round bottom flask. A magnetic stirrer was placed under the flask, a reflux condenser and a pressure equalizing additional funnel were connected to the flask in turn. $0.2 \mathrm{ml}$ citric acid was dissolved in $100 \mathrm{ml}$ of ethanol, and the mixture was shifted to the pressure equalizing additional funnel and dropwise added to the flask under the argon atmosphere in 2 hours. After the reaction was completed, the upper suspended ethanol was removed, and the final mixture was heated in a water bath at $78{ }^{\circ} \mathrm{C}$ to evaporate the remaining ethanol under argon atmosphere. In the end, the consequent viscous liquid was dried under a vacuum line for 7 hours. The molecular structure of the product was analyzed by proton nuclear magnetic resonance $\left({ }^{1} \mathrm{H} \mathrm{NMR}\right)$ using a Bruker Ultrashield $300 \mathrm{MHz}$ spectrometer, with DMSO-d6 as solvent and TMS as internal standard. The molecular structure and empirical formula of DCi are summarized in Table 2.

In this research, DCi was added in $1 \mathrm{wt} \%$ to $\mathrm{MO}$ to form a homogeneous mixture at room temperature through magnetic stirring for 6 hours, and ultrasonicating for 0.5 hour. In addition, to study the stability of $1 \mathrm{wt} \% \mathrm{DCi}$ in $\mathrm{MO}$, the mixtures were centrifuged at $6,500 \mathrm{rpm}$ for $10 \mathrm{~min}$, and then observed the appearance of the mixture after 24, 168, and 720 hours. Thermogravimetric analysis (TGA) of $\mathrm{MO}$ and DCi were conducted with a TA Instrument Q500 from ambient temperature to $600{ }^{\circ} \mathrm{C}$ at a heating rate of $10^{\circ} \mathrm{C} / \mathrm{min}$ and a flow rate of $20 \mathrm{~mL} / \mathrm{min}$ in air. Dynamic viscosity measurements of $\mathrm{MO}$, pure $\mathrm{DCi}$,

Table 1 Properties of MO used in this study.

\begin{tabular}{cccccc}
\hline $\begin{array}{c}\text { Density at } \\
15{ }^{\circ} \mathrm{C} \\
(\mathrm{g} / \mathrm{mL})\end{array}$ & $\begin{array}{c}\text { Kinematic } \\
\text { viscosity }\left(\mathrm{mm}^{2} / \mathrm{s}\right)\end{array}$ & $\begin{array}{c}\text { Viscosity } \\
\text { index }\end{array}$ & $\begin{array}{c}\text { Flash } \\
\text { point } \\
\left({ }^{\circ} \mathrm{C}\right)\end{array}$ & $\begin{array}{c}\text { Pour } \\
\text { point } \\
\left({ }^{\circ} \mathrm{C}\right)\end{array}$ \\
\hline 0.8668 & 45.91 & 6.676 & 97 & 234 & -12 \\
\hline
\end{tabular}

Table 2 Molecular structure and empirical formula of DCi.

\begin{tabular}{cccc}
\hline \multicolumn{2}{c}{ Molecular structure } & $\begin{array}{c}\text { Empirical } \\
\text { formula }\end{array}$ \\
\hline Cation & Anion & \\
\hline
\end{tabular}


and $1 \mathrm{wt} \% \mathrm{DC}+\mathrm{MO}$ were carried out by a Brookfield DV2T viscometer with a thermosel system.

Tribological tests were conducted in a reciprocating ball-on-flat tribometer (Fig. 1(a)), with a heater to run tests at room temperature and $100{ }^{\circ} \mathrm{C}$, respectively. In the reciprocating tests, AISI 52100 steel disks (hardness $\approx 22.3 \mathrm{HRC}$ and $\mathrm{R} a \approx 0.008 \mu \mathrm{m}$ ) slid against AISI 52100 steel balls (hardness $\approx 58$ HRC and $R a \approx$ $0.53 \mu \mathrm{m}$ ) with diameter of $1.5 \mathrm{~mm}$. The tribotests were carried out under a normal load of $2 \mathrm{~N}$, which corresponds to a mean Hertz contact pressure of $1.34 \mathrm{GPa}$ and a maximum Hertz contact pressure of $2.02 \mathrm{GPa}$. The sliding speed for each test was set to $0.05 \mathrm{~m} / \mathrm{s}$ with frequency of $5 \mathrm{~Hz}$, stroke length of $5 \mathrm{~mm}$, and sliding distance of $200 \mathrm{~m}$.

At least three tests were performed under the same conditions for each lubricant at room temperature and $100{ }^{\circ} \mathrm{C}$. Prior to each test, $1 \mathrm{~mL}$ of lubricant was added on the disk surface and no additional lubricant was added during the testing process. Once completing each trial, the disk was placed in an ultrasonic cleaner with isopropyl alcohol (99.5\%) until the sample was cleaned completely, and then dried in air. Friction coefficients were recorded over time and calculated as average of each running. After tests, an Olympus BH-2 optical microscope was used to measure the width of wear tracks and at least 15 measurements were taken along each wear track. The wear volume was calculated according to Eq. (1) [34]. A Nanovea ST 400 profilometer was also used to study the 3-dimensional (3D) images of the wear tracks. A Tescan Mira3 scanning electron microscope (SEM) and energy dispersive spectrometer (EDS) were used to analyze

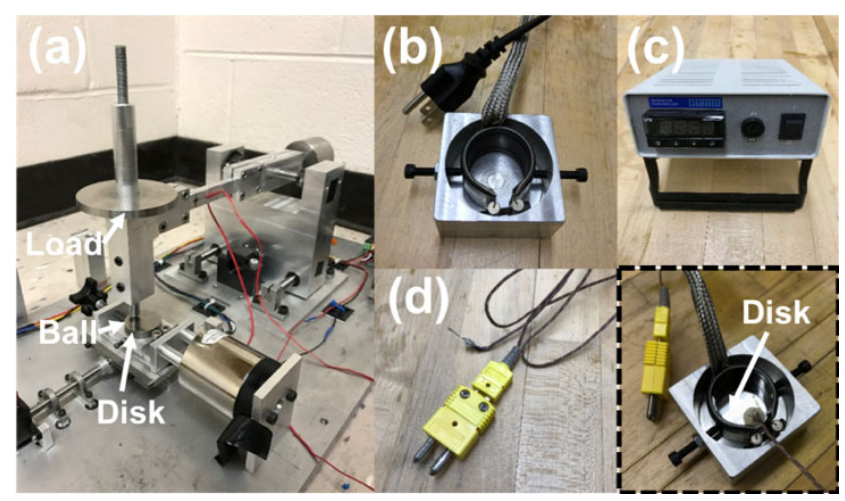

Fig. 1 Images of (a) reciprocating ball-on-flat tribometer and (b-d) experimental kit used for tribotests in high temperature: (b) sample holder, (c) temperature controller, and (d) thermal couple. the wear mechanism and surface interaction between the steel disks and steel balls.

$$
\begin{aligned}
& V_{f}=L_{s}\left[R_{f}^{2} \arcsin \left(\frac{W}{2 R_{f}}\right)-\frac{W}{2}\left(R_{f}-h_{f}\right)\right]+\frac{\pi}{3} h_{f}^{2}\left(3 R_{f}-h_{f}\right) \\
& h_{f}=R_{f}-\sqrt{R_{f}^{2}-\frac{W^{2}}{4}}
\end{aligned}
$$

where $V_{f}$ is wear volume, $L_{\mathrm{s}}$ is stroke length, $R_{f}$ is radius of the ball, $W$ is width of the wear scar, and $h_{f}$ is wear depth.

\section{Results and discussion}

\subsection{NMR and stability tests}

NMR spectrum was carried out to analyze and to confirm the ionic structure of DCi and the results are shown in Fig. 2. The abbreviations used below are to designate the multiplicities: $\mathrm{s}=$ singlet, and $\mathrm{t}=$ triplet. $\delta=4.46\left(\mathrm{~s}, 13 \mathrm{H}, \mathrm{NH}_{2}, \mathrm{OH}\right)$ corresponds to hydrogens of $-\mathrm{OH}$ and $-\mathrm{NH}$ from the IL cation. When $\delta=$ 3.55-3.60 ( $\mathrm{t}, 12 \mathrm{H}, \mathrm{CH}_{2}, \mathrm{CH}_{2}, \mathrm{CH}_{2}, \mathrm{CH}_{2}, \mathrm{CH}_{2}, \mathrm{CH}_{2}$ ), the peaks are related to the hydrogens of $-\mathrm{CH}_{2}$ also in cations. When $\delta=2.77-2.85\left(\mathrm{t}, 12 \mathrm{H}, \mathrm{N}-\mathrm{CH} 2, \mathrm{~N}-\mathrm{CH}_{2}\right.$, $\left.\mathrm{N}-\mathrm{CH}_{2}, \mathrm{~N}-\mathrm{CH}_{2}, \mathrm{~N}-\mathrm{CH}_{2}, \mathrm{~N}-\mathrm{CH}_{2}\right)$, the peaks correspond to the hydrogens of $-\mathrm{CH}_{2}$, whose carbon is connected with the nitrogen from cations of DCi. The peak for $\delta=$ 2.5 is the characteristic peak of hydrogen in DMSO-d6. When $\delta=2.33-2.4\left(\mathrm{~s}, 4 \mathrm{H}, \mathrm{C}=\mathrm{O}-\mathrm{CH}_{2}\right)$, the peaks are related to the hydrogen in $\mathrm{C}=\mathrm{O}-\mathrm{CH}_{2}$ of anions. This spectrum confirms the ionic structure of DCi.

Figure 3 shows the stability samples of $1 \mathrm{wt} \% \mathrm{DCi}$ in MO. From the Fig. 3, there is no visual deposit on the bottom of each centrifugal capsule after observation for 24, 168, and 720 hours. These results confirm the good stability of $1 \mathrm{wt} \% \mathrm{DC}$ in MO.

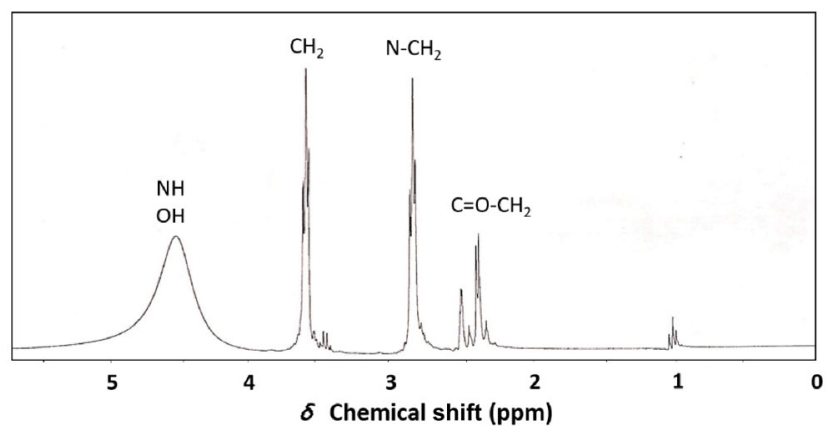

Fig. 2 NMR spectrum of DCi. 


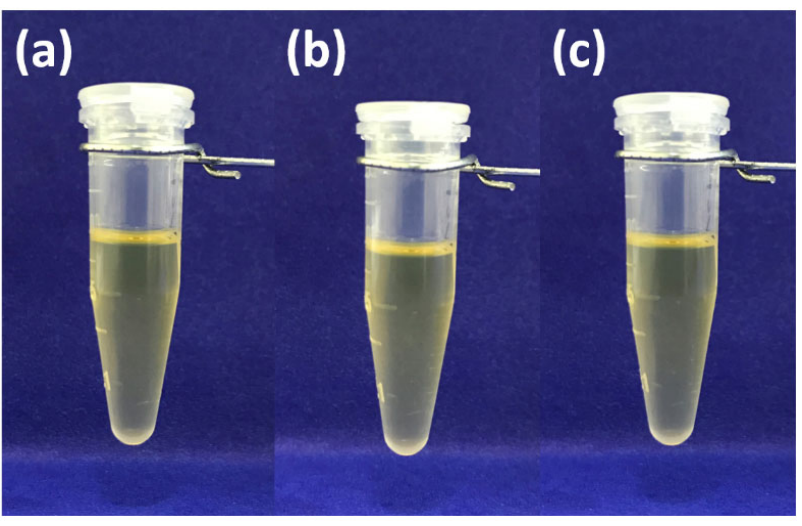

Fig. 3 Proof of stability of 1 wt $\%$ DCi in MO after (a) 24, (b) 168 , and (c) $720 \mathrm{~h}$.

\subsection{Thermal stability and viscosity of the lubricants}

The thermal stability of $\mathrm{MO}$, pure $\mathrm{DCi}$, and the mixture $1 \mathrm{wt} \% \mathrm{DCi}+\mathrm{MO}$ were examined by thermogravimetric analysis (TGA) and the results are summarized in Table 3 and Fig. 4. MO has higher thermal stability than pure DCi, with onset decomposition temperatures of 291.2 and $191.2{ }^{\circ} \mathrm{C}$, respectively. When $1 \mathrm{wt} \% \mathrm{DCi}$ is added into the base $\mathrm{MO}$, the mixture exhibits slightly higher thermal stability than $\mathrm{MO}$, with an onset temperature of $300.4^{\circ} \mathrm{C}$.

Viscosity is one of the most important physical properties of a lubricant. Viscosity tests were performed with $\mathrm{MO}$, pure $\mathrm{DCi}$, and the mixture of $1 \mathrm{wt} \% \mathrm{DCi}+$ MO. The average dynamic viscosity as a function of

Table 3 Thermal stability of MO, DCi, and $1 \mathrm{wt} \% \mathrm{DCi}+\mathrm{MO}$.

\begin{tabular}{cc}
\hline Lubricant & Onset temperature $\left({ }^{\circ} \mathrm{C}\right)$ \\
\hline $\mathrm{MO}$ & 291.2 \\
$\mathrm{DCi}$ & 191.2 \\
$1 \mathrm{wt} \% \mathrm{DCi}+\mathrm{MO}$ & 300.4 \\
\hline
\end{tabular}

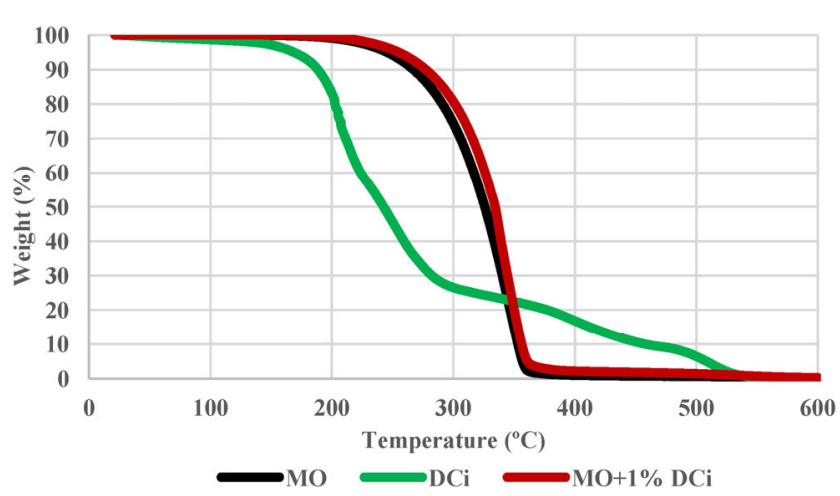

Fig. 4 Experimental TGA for MO, DCi, and $1 \mathrm{wt} \% \mathrm{DCi}+\mathrm{MO}$. temperature of these lubricants are shown in Fig. 5 and Table 4. It is well known that ion-ion interactions and hydrogen bonding between molecules will impact the lubricant viscosity. In general, greater chemical interactions lead to higher viscosity [29]. Pure DCi shows a higher viscosity than $\mathrm{MO}$ at room temperature due to the hydrogen bondings between cations and anions. When $1 \mathrm{wt} \% \mathrm{DCi}$ was added into $\mathrm{MO}$, the viscosity of the mixture is increased slightly compared to neat MO.

\subsection{Tribological properties}

The lubricating ability of $\mathrm{MO}$ and $1 \mathrm{wt} \% \mathrm{DCi}+\mathrm{MO}$ at room temperature and $100{ }^{\circ} \mathrm{C}$ under reciprocating steel-steel contact mode were studied using a ballon-flat tribometer. Figure 6 shows the average value of the friction coefficient of the lubricants at room temperature and $100{ }^{\circ} \mathrm{C}$. Adding $1 \mathrm{wt} \%$ DCi to the MO reduced the friction coefficient at both temperatures. Increasing the temperature, increased the friction coefficient when the steel sliding surfaces are lubricated
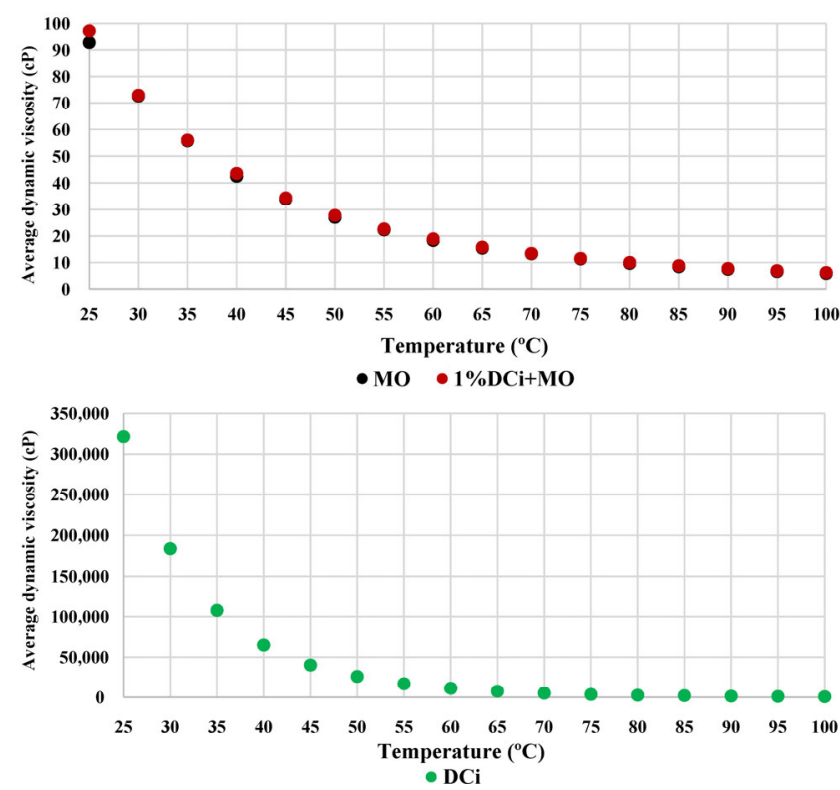

Fig. 5 Viscosity of MO, pure DCi, and mixture $1 \mathrm{wt} \% \mathrm{DCi}+\mathrm{MO}$.

Table 4 Viscosity of MO, DCi, and $1 \mathrm{wt} \% \mathrm{DCi}+\mathrm{MO}$.

\begin{tabular}{cccc}
\hline \multirow{2}{*}{ Lubricant } & \multicolumn{3}{c}{ Dynamic viscosity (cP) } \\
\cline { 2 - 4 } & $25^{\circ} \mathrm{C}$ & $40{ }^{\circ} \mathrm{C}$ & $100{ }^{\circ} \mathrm{C}$ \\
\hline $\mathrm{MO}$ & 92.78 & 42.54 & 5.90 \\
$\mathrm{DCi}$ & $321,691.43$ & $65,097.14$ & 941.21 \\
$1 \mathrm{wt} \% \mathrm{DCi}+\mathrm{MO}$ & 97.17 & 43.58 & 6.22 \\
\hline
\end{tabular}




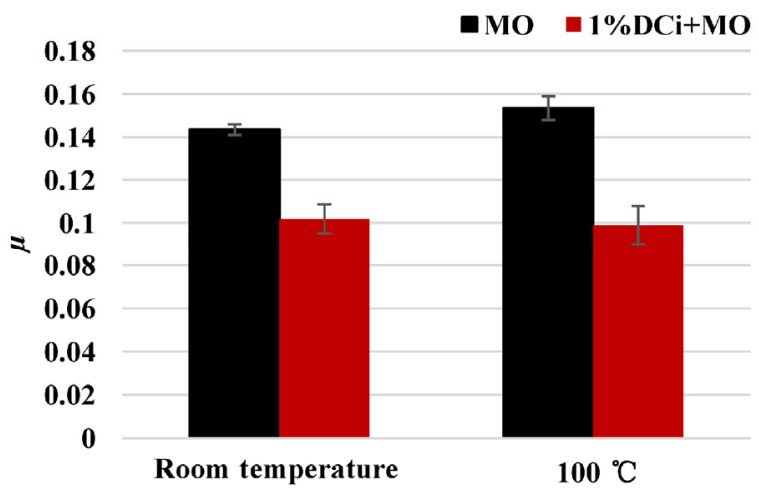

Fig. 6 Average friction coefficients as a function of temperature.

with $\mathrm{MO}$, however when $1 \mathrm{wt} \% \mathrm{DC}+\mathrm{MO}$ is used as lubricant, the friction coefficient remains constant. A maximum friction reduction of $35.5 \%$ is obtained when the mixture was used as lubricant compared with neat $\mathrm{MO}$ at $100{ }^{\circ} \mathrm{C}$.

Figure 7 summarizes the wear volumes of the sliding disks after tests lubricated with $\mathrm{MO}$ and $1 \mathrm{wt} \% \mathrm{DCi}+\mathrm{MO}$ at room temperature and $100{ }^{\circ} \mathrm{C}$. At room temperature, the presence of DCi in the lubricant slightly increased the wear volume of the steel disks. However, at the higher temperature studied, the disk lubricated with $1 \mathrm{wt} \%$ DCi+MO led to a less wear loss with a wear reduction of $59.4 \%$ with respect to the MO. These results confirm the good lubricating ability of $1 \mathrm{wt} \%$ $\mathrm{DCi}+\mathrm{MO}$ at high temperature.

The optical micrographs of the worn balls lubricated with $\mathrm{MO}$ and $1 \mathrm{wt} \% \mathrm{DCi}+\mathrm{MO}$ at room temperature and $100{ }^{\circ} \mathrm{C}$ are shown in Fig. 8. The wear scars (Figs. 8(b) and 8(d)) obtained at high temperature are larger than the ones formed at room temperature (Figs. 8(a) and 8(c)). There is no significant difference between the wear scars obtained after tests run at room temperature (Figs. 8(a) and 8(c)). However, adding DCi to MO reduced the size of the steel ball

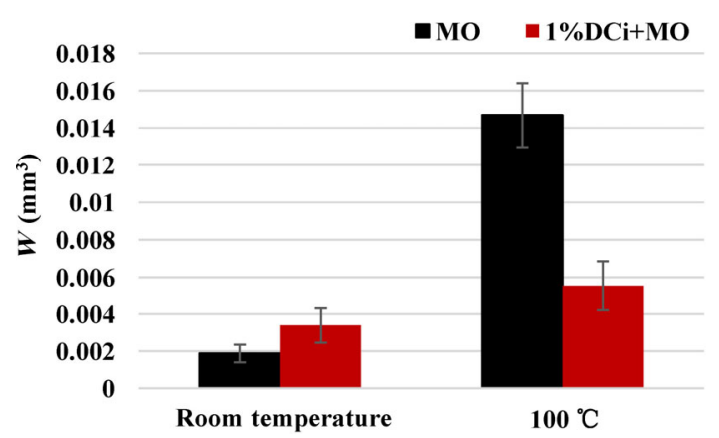

Fig. 7 Wear volume of steel disks as a function of temperature.
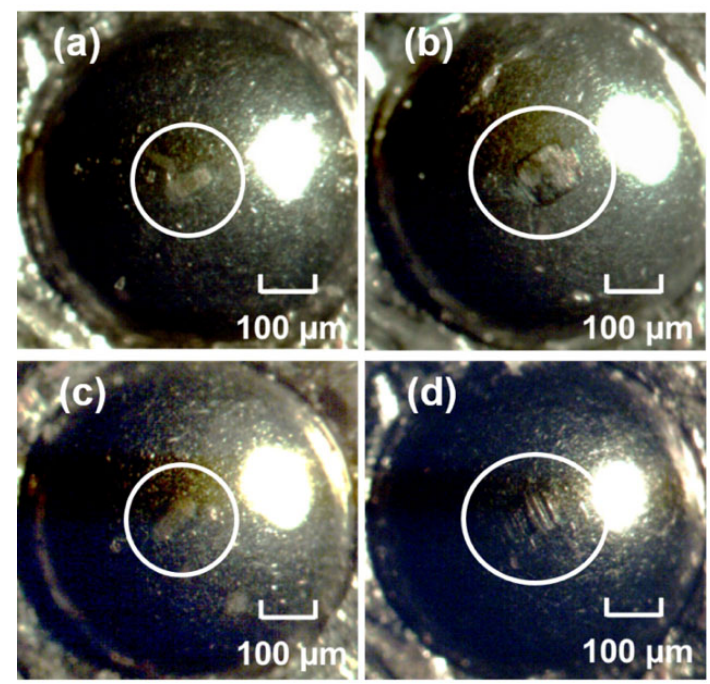

Fig. 8 Optical images of worn balls after lubricated with (a) $\mathrm{MO}$ at room temperature, (b) $\mathrm{MO}$ at $100{ }^{\circ} \mathrm{C}$, (c) $1 \mathrm{wt} \% \mathrm{DCi}+\mathrm{MO}$ at room temperature, and (d) $1 \mathrm{wt} \% \mathrm{DCi}+\mathrm{MO}$ at $100{ }^{\circ} \mathrm{C}$.

wear track (Figs. 8(b) and 8(d)) at high temperature, confirming that the presence of DCi in the lubricant improves the wear prevention of the sliding disks as well as the pairing components.

Figure 9 shows the optical images of the worn surfaces of the steel disks after frictional tests lubricated with $\mathrm{MO}$ and $1 \mathrm{wt} \% \mathrm{DCi}+\mathrm{MO}$. As expected, increasing the temperature increased the wear volume on the steel disks for both lubricants. However, when DCi was used as additive at $100{ }^{\circ} \mathrm{C}$, a more uniform and narrower wear track is observed compared to that obtained after a test lubricated with neat MO. For both lubricants, clear abrasive marks parallel to the sliding direction are observed on steel surfaces at $100^{\circ} \mathrm{C}$. In addition to the plowing effect, plastic deformation and pits can be observed on the worn steel surface when lubricated with $\mathrm{MO}$ at $100{ }^{\circ} \mathrm{C}$.

In order to verify the wear depth variations of the steel disks when lubricated with $\mathrm{MO}$ and $1 \mathrm{wt} \%$ $\mathrm{DCi}+\mathrm{MO}$ under room temperature and $100{ }^{\circ} \mathrm{C}$, Nanovea ST 400 profilometer was used to obtain the 3D images (Fig. 10) and 2D images (Fig. 11) of the wear tracks on the steel disks. In Figs. 10 and 11, the depth of the wear track increases as the temperature goes up for both lubricants. Comparing the images in Figs. 10(a and c) and 11(a and c), wear tracks after a test lubricated with $\mathrm{MO}$ are narrower and shallower than those obtained after a test lubricanted with $1 \mathrm{wt} \% \mathrm{DC}+\mathrm{MO}$ at room temperature. When the 

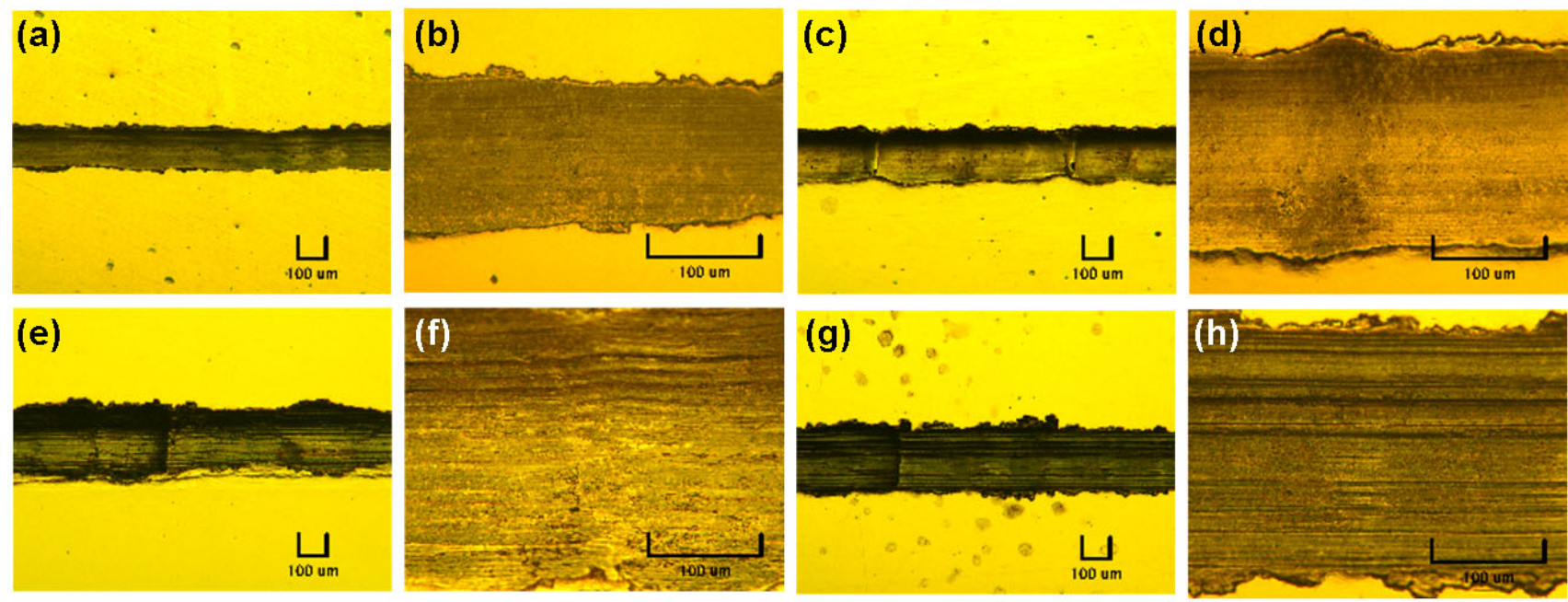

Fig. 9 Optical images of wear tracks on the steel disks after sliding $200 \mathrm{~m}$ and lubricated with (a and b) MO at room temperature, (c and d) $1 \mathrm{wt} \% \mathrm{DCi}+\mathrm{MO}$ at room temperature, (e and $\mathrm{f}$ ) $\mathrm{MO}$ at $100{ }^{\circ} \mathrm{C}$, (g and h) $1 \mathrm{wt} \% \mathrm{DCi}+\mathrm{MO}$ at $100{ }^{\circ} \mathrm{C}$. Left images display with $50 \times$ zoom and right images display with $200 \times$ zoom.

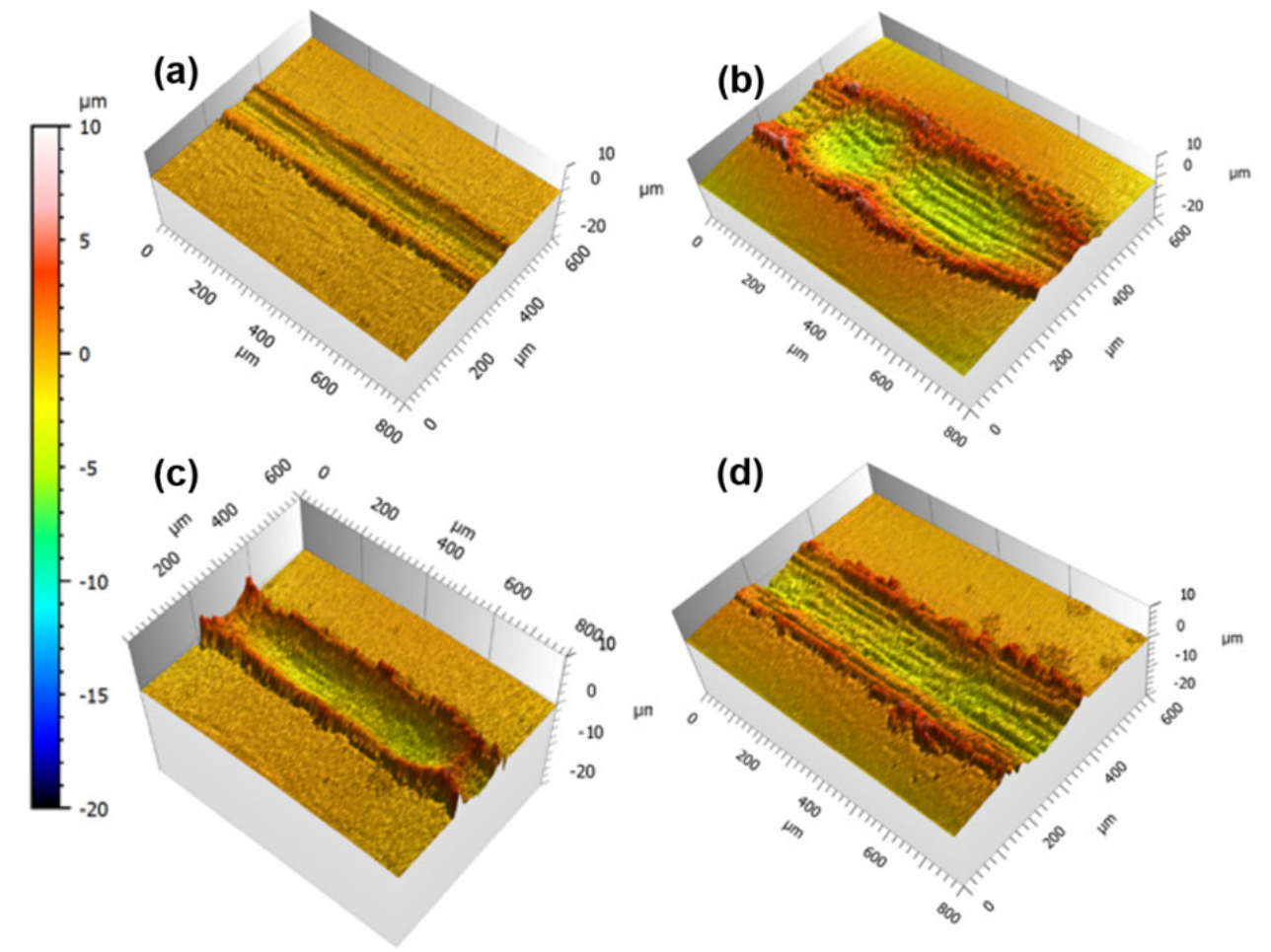

Fig. $103 \mathrm{D}$ profilometer images of wear tracks on the steel disks after lubricated with (a) $\mathrm{MO}$ at room temperature, (b) $\mathrm{MO}$ at $100{ }^{\circ} \mathrm{C}$, (c) $1 \mathrm{wt} \% \mathrm{DCi}+\mathrm{MO}$ at room temperature, and (d) $1 \mathrm{wt} \% \mathrm{DCi}+\mathrm{MO}$ at $100{ }^{\circ} \mathrm{C}$.

temperature increases to $100{ }^{\circ} \mathrm{C}$, the mixture outperforms MO in preventing wear on the steel disks. In Figs. 10(b) and 11(b), both the depth and width of the wear tracks are larger than the one in Figs. 10(d) and $11(\mathrm{~d})$.

SEM and EDS were used to analyze the wear mechanism and surface interactions between rubbing components. The SEM micrographs of wear tacks on the steel disks after lubricated with $\mathrm{MO}$ and $1 \mathrm{wt} \%$ $\mathrm{DCi}+\mathrm{MO}$ at room temperature and $100{ }^{\circ} \mathrm{C}$ are shown in Fig. 12. The abrasive marks can be seen in all the images, but particularly at high temperature for both 
(a)

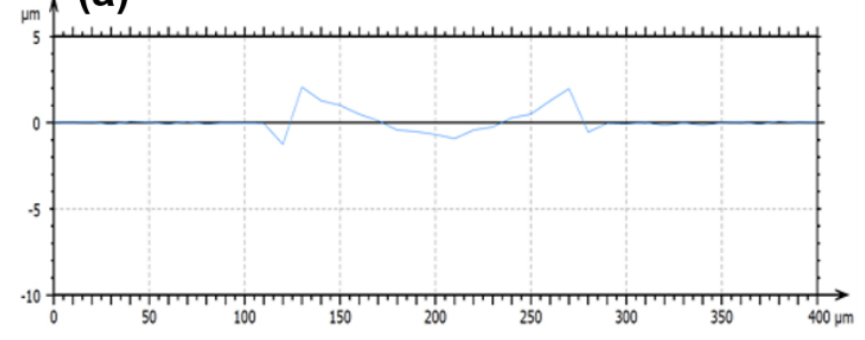

(c)

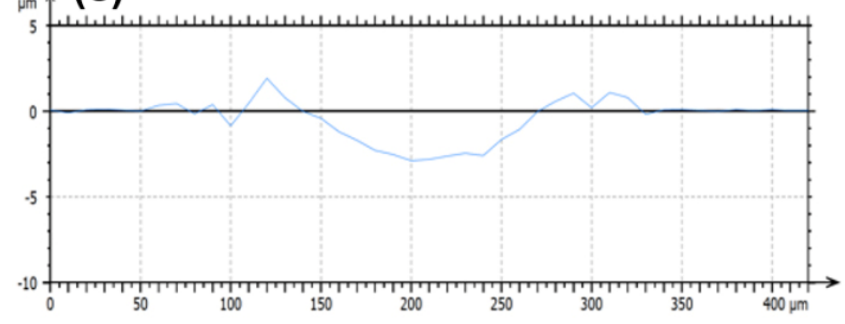

(b)

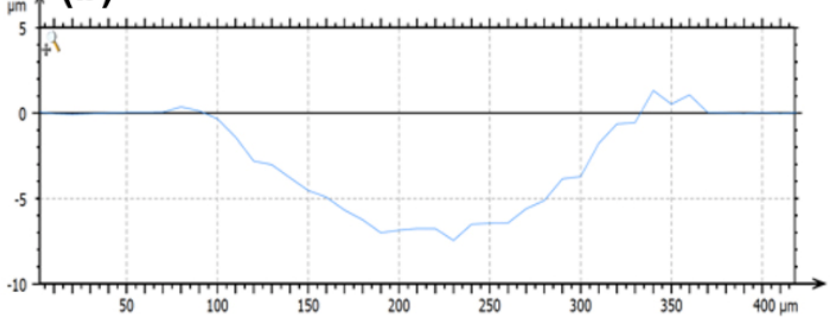

(d)

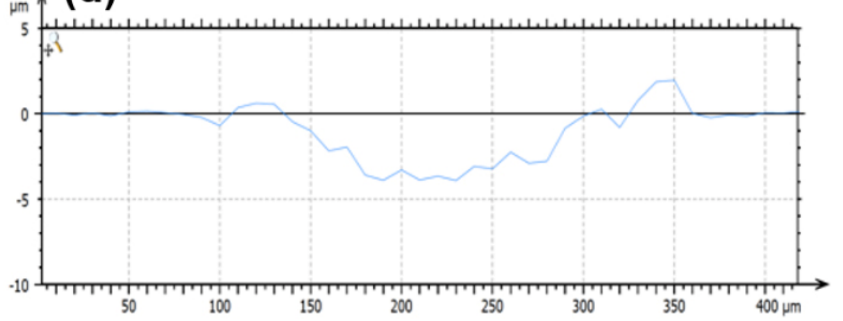

Fig. 11 2D profiles of wear tracks on the steel disks after lubricated with (a) MO at room temperature, (b) $\mathrm{MO}$ at $100{ }^{\circ} \mathrm{C},(\mathrm{c}) 1 \mathrm{wt} \%$ $\mathrm{DCi}+\mathrm{MO}$ at room temperature, and (d) $1 \mathrm{wt} \% \mathrm{DCi}+\mathrm{MO}$ at $100^{\circ} \mathrm{C}$.
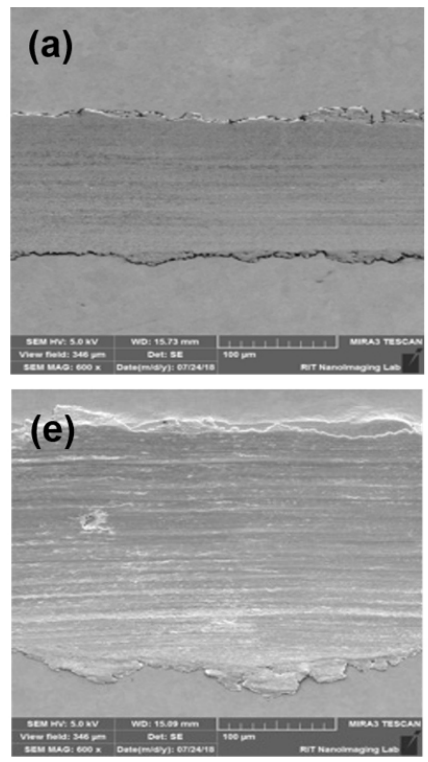
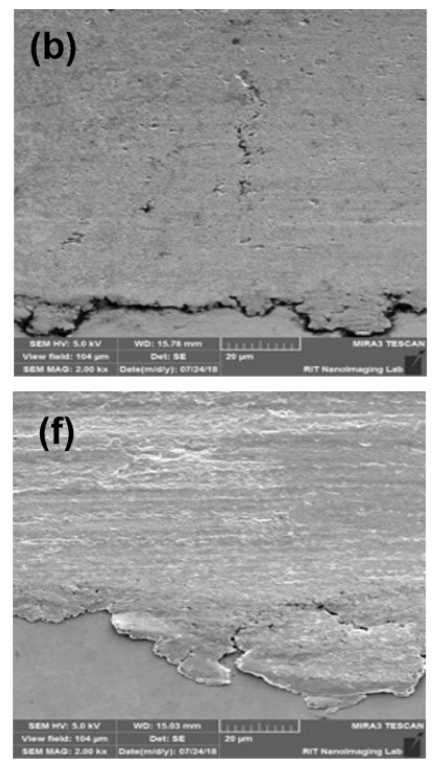
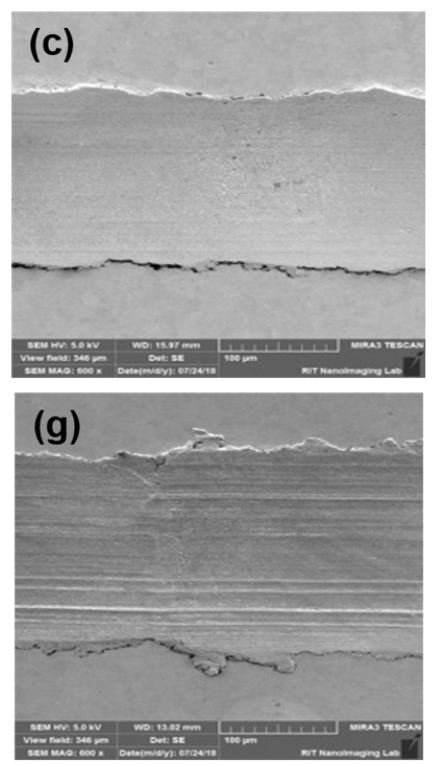
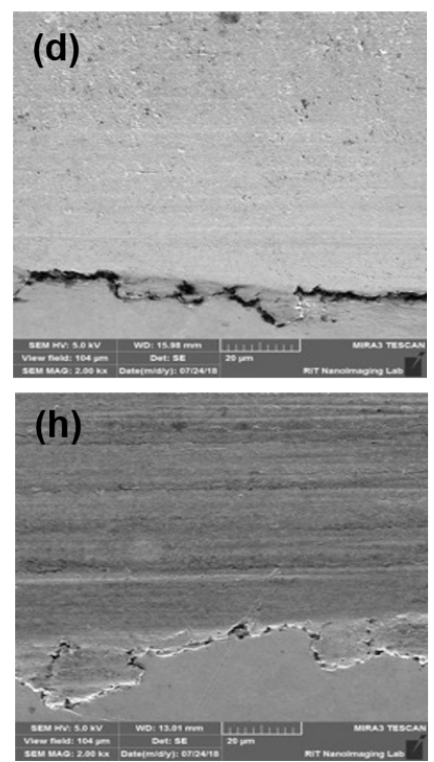

Fig. 12 SEM micrographs of wear tracks on the steel disks after a sliding distance of $200 \mathrm{~m}$ and lubricated with (a and b) MO at room temperature, (c and d) $1 \mathrm{wt} \% \mathrm{DCi}+\mathrm{MO}$ at room temperature, (e and f) $\mathrm{MO}$ at $100{ }^{\circ} \mathrm{C},\left(\mathrm{g}\right.$ and h) $1 \mathrm{wt} \% \mathrm{DCi}+\mathrm{MO}$ at $100{ }^{\circ} \mathrm{C}$. Left images display with $600 \times$ zoom and right images display with $2,000 \times$ zoom.

lubricants (Figs. 12(e)-12(h)). An important component of plastic deformation with material accumulated at the borders of the wear tracks is also seem at both temperatures.

In order to understand the lubricating mechanism of DCi as lubricant additive at high temperature, EDS analysis was carried out inside and outside of the wear tracks after a test lubricated with $\mathrm{MO}$ and
$1 \mathrm{wt} \% \mathrm{DCi}+\mathrm{MO}$ at $100{ }^{\circ} \mathrm{C}$, and results are shown in Figs. 13(a) and 13(b). Both worn surfaces show higher amount of oxygen and a slightly higher carbon inside the wear track compared to the outside. However, according to the spectra, the amount of oxygen on the worn surface is higher when the sample surface was lubricated with $1 \mathrm{wt} \% \mathrm{DC}+\mathrm{MO}$, where the oxygen is homogeneously distributed inside of the wear track 

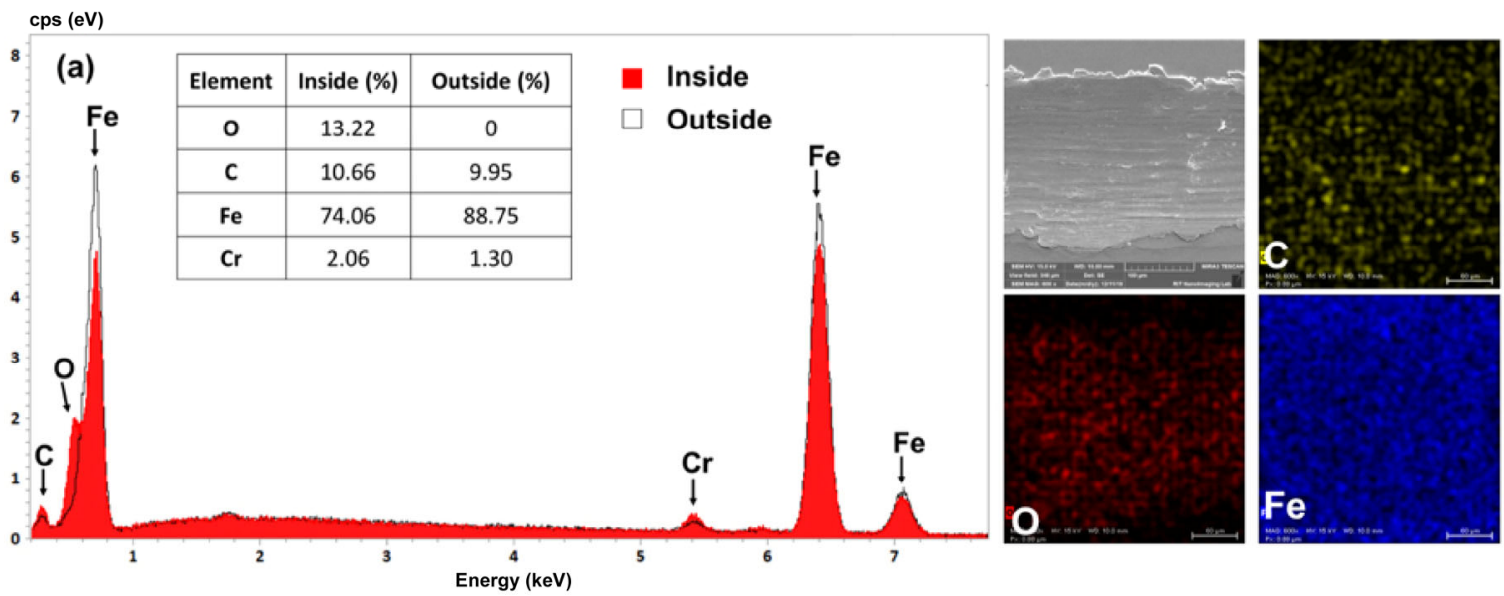

cps (eV)
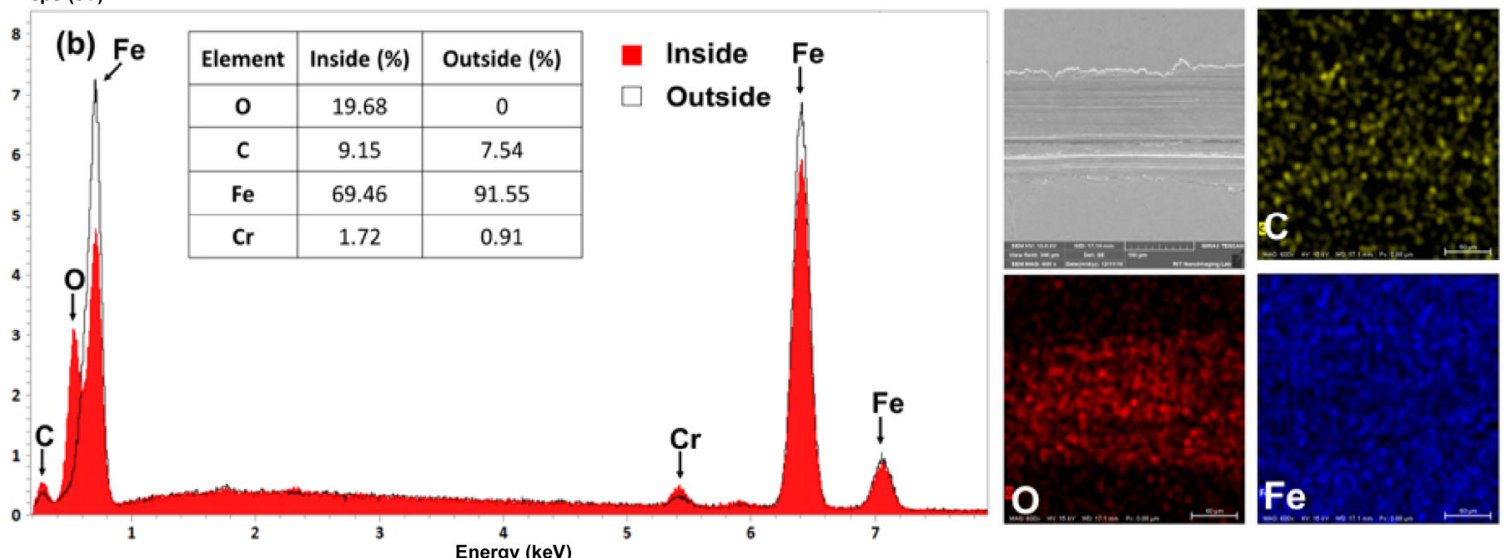

Fig. 13 EDS spectrum inside and outside the wear track and element mapping after lubricated with (a) $\mathrm{MO}$ at $100{ }^{\circ} \mathrm{C}$ and (b) $1 \mathrm{wt} \%$ $\mathrm{DCi}+\mathrm{MO}$ at $100^{\circ} \mathrm{C}$.

(see the element mapping in Fig. 13(b)). This oxygenrichened tribolayer may be responsible for the good lubricating behavior when $1 \mathrm{wt} \% \mathrm{DCi}$ is present in the lubricating system $[29,35]$.

\section{Conclusions}

The tribological ability of a new synthesized protic ionic liquid tri-[bis(2-hydroxyethylammonium)] citrate (DCi) is studied as additive to a base MO for a steel-steel contact mode at room temperature and $100{ }^{\circ} \mathrm{C}$. When $1 \mathrm{wt} \% \mathrm{DCi}$ is added into $\mathrm{MO}$, lower friction coefficient at both temperatures are observed compared to $\mathrm{MO}$, with friction reductions of $29.0 \%$ at room temperature, and $35.5 \%$ at $100{ }^{\circ} \mathrm{C}$. In addition to these promising friction results, $1 \mathrm{wt} \% \mathrm{DCi}+\mathrm{MO}$ also exhibits an excellent anti-wear performance at $100{ }^{\circ} \mathrm{C}$ where the wear reduction reaches up to $59.4 \%$ compared to MO. Abrasive marks and plastic deformation with accumulated material along the borders of the wear tracks can be seen from optical and SEM images of the worn surfaces after tests lubricated with $\mathrm{MO}$ and $1 \mathrm{wt} \% \mathrm{DC}+\mathrm{i}+\mathrm{O}$. In particular, when $1 \mathrm{wt} \%$ is added to $\mathrm{MO}$, wear tracks obtained after tests at high temperature are narrower and swallower than those obtained after a test lubricated with MO. From EDS analysis, a carbon and oxygen-richened tribolayer is formed on the surface when DCi was used as additive at $100{ }^{\circ} \mathrm{C}$, that may be responsible for improving the friction and wear performance at this temperature.

Open Access This article is licensed under a Creative Commons Attribution 4.0 International Li-cense, which permits use, sharing, adaptation, distribution and reproduction in any medium or for-mat, as long as you give appropriate credit to the original author(s) and the source, provide a link to the Creative Commons licence, and indicate if changes were made. 
The images or other third party material in this article are included in the article's Creative Commons licence, unless indicated otherwise in a credit line to the material. If material is not in-cluded in the article's Creative Commons licence and your intended use is not permitted by statutory regulation or exceeds the permitted use, you will need to obtain permission directly from the copyright holder.

To view a copy of this licence, visit http://creativecommons.org/licenses/by/4.0/.

\section{References}

[1] Holmberg K, Erdemir A. Influence of tribology on global energy consumption, costs and emissions. Friction 5(3): 263-284 (2017)

[2] Spikes H. Friction modifier additives. Tribol Lett 60(1): 5 (2015)

[3] Ye C, Liu W, Chen Y, Yu L. Room-temperature ionic liquids: A novel versatile lubricant. Chem Commun 7(21): 2244-2245 (2001)

[4] Li Z P, Ren T H. Synergistic effects between alkylphosphateammonium ionic liquid and alkylphenylborate as lubricant additives in rapeseed oil. Tribol Int 109: 373-381 (2017)

[5] Qu J, Truhan J J, Dai S, Luo H, Blau P J. Ionic liquids with ammonium cations as lubricants or additives. Tribol Lett 22(3): 207-214 (2006)

[6] Cai M R, Liang Y M, Yao M H, Xia Y Q, Zhou F, Liu W M. Imidazolium ionic liquids as antiwear and antioxidant additive in poly(ethylene glycol) for steel/steel contacts. ACS Appl Mater Interfaces 2(3): 870-876 (2010)

[7] Mahrova M, Pagano F, Pejakovic V, Valea A, Kalin M, Igartua A, Tojo E. Pyridinium based dicationic ionic liquids as base lubricants or lubricant additives. Tribol Int $\mathbf{8 2}$ : 245-254 (2015)

[8] Hernández Battez A, Bartolomé M, Blanco D, Viesca J L, Fernández-González A, González R. Phosphonium cationbased ionic liquids as neat lubricants: Physicochemical and tribological performance. Tribol Int 95: 118-131 (2016)

[9] Guo H, Liu R, Fuentes-Aznar A, Victoria P I. Friction and wear properties of halogen-free and halogen-containing ionic liquids used as neat lubricants, lubricant additives and thin lubricant layers. In 2017 International Design Engineering Technical Conferences and Computers and Information in Engineering Conference, Cleveland, Ohio, USA, 2017.

[10] Zhou Y, Qu J. Ionic liquids as lubricant additives: A review. ACS Appl Mater Interfaces 9(4): 3209-3222 (2017)
[11] Arcifa A, Rossi A, Espinosa-Marzal R M, Spencer N D. Influence of environmental humidity on the wear and friction of a silica/silicon tribopair lubricated with a hydrophilic ionic liquid. ACS Appl Mater Interfaces 8(5): 2961-2973 (2016)

[12] Matczak L, Johanning C, Gil E, Guo H, Smith T W, Schertzer M, Iglesias P. Effect of cation nature on the lubricating and physicochemical properties of three ionic liquids. Tribiol Int 124: 23-33 (2018)

[13] Mistry K, Fox M F, Priest M. Lubrication of an electroplated nickel matrix silicon carbide coated eutectic aluminium-silicon alloy automotive cylinder bore with an ionic liquid as a lubricant additive. Proc Inst Mech Eng Part J J Eng Tribol 223(3): 563-569 (2009)

[14] Jiménez A E, Bermúdez M D. Short alkyl chain imidazolium ionic liquid additives in lubrication of three aluminium alloys with synthetic ester oil. Tribol-Mater Surf Interfaces 6(3): 109-115 (2012)

[15] Pejaković V, Kronberger M, Mahrova M, Vilas M, Tojo E, Kalin M. Pyrrolidinium sulfate and ammonium sulfate ionic liquids as lubricant additives for steel/steel contact lubrication. Proc Inst Mech Eng Part J J Eng Tribol 226(11): 923-932 (2012)

[16] Liu X Q, Zhou F, Liang Y M, Liu W M. Tribological performance of phosphonium based ionic liquids for an aluminum-on-steel system and opinions on lubrication mechanism. Wear 261(10): 1174-1179 (2006)

[17] Yu B, Bansal D G, Qu J, Sun X Q, Luo H M, Dai S, Blau P J, Bunting B G, Mordukhovich G, Smolenski D J. Oilmiscible and non-corrosive phosphonium-based ionic liquids as candidate lubricant additives. Wear 289: 58-64 (2012)

[18] Patel A, Guo H, Iglesias P. Study of the lubricating ability of protic ionic liquid on an aluminum-steel contact. Lubricants 6(3): 66 (2018)

[19] Del Sol I, Gámez A J, Rivero A, Iglesias P. Tribological performance of ionic liquids as additives of water-based cutting fluids. Wear 426-427: 845-852 (2019)

[20] Ratti R. Ionic liquids: Synthesis and applications in catalysis. Adv Chem 2014: 729842 (2014)

[21] Kondo H. Protic ionic liquids with ammonium salts as lubricants for magnetic thin film media. Tribol Lett 31(3): 211-218 (2008)

[22] Duan Z Y, Gu Y L, Zhang J, Zhu L Y, Deng Y Q. Protic pyridinium ionic liquids: Synthesis, acidity determination and their performances for acid catalysis. J Mol Catal A Chem 250(1-2): 163-168 (2006)

[23] Tong X L, Ma Y, Li Y D. An efficient catalytic dehydration of fructose and sucrose to 5-hydroxymethylfurfural with protic ionic liquids. Carbohydr Res 345(12): 1698-1701 (2010) 
[24] Hayes R, Imberti S, Warr G G, Atkin R. Effect of cation alkyl chain length and anion type on protic ionic liquid nanostructure. J Phys Chem C 118(25): 13998-14008 (2014)

[25] Shmukler L E, Gruzdev M S, Kudryakova N O, Fadeeva Y A, Kolker A M, Safonova L P. Thermal behavior and electrochemistry of protic ionic liquids based on triethylamine with different acids. RSC Adv 6(111): 109664-109671 (2016)

[26] Walden P. Molecular weights and electrical conductivity of several fused salts. Bull Acad Imper Sci (St. Petersburg) 1800: 405-422 (1914)

[27] Vega M R O, Parise K, Ramos L B, Boff U, Mattedi S, Schaeffer L, Malfatti C F. Protic ionic liquids used as metal-forming green lubricants for aluminum: Effect of anion chain length. Mater Res 20(3): 675-687 (2017)

[28] Espinosa T, Sanes J, Jiménez A E, Bermúdez M D. Protic ammonium carboxylate ionic liquid lubricants of OFHC copper. Wear 303(1-2): 495-509 (2013)

[29] Greaves T L, Drummond C J. Protic ionic liquids: Properties and applications. Chem Rev 108(1): 206-237 (2008)

[30] Canter N. Special Report: Additive challenges in meeting

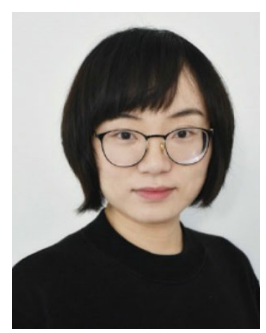

Hong GUO. She received her B.E. degree in metal material in 2010 from Zhengzhou University, Zhengzhou, China. Then she earned her M.S. degree in functional metal materials from Jinan University, Guangzhou, China, in 2014. Now

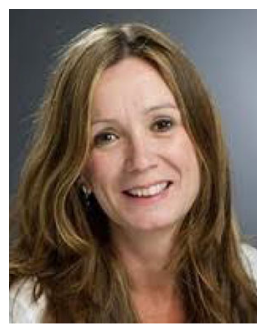

Patricia IGLESIAS. She earned her Ph.D. in mechanical engineering with focus on tribology from the Polytechnic University of Cartagena (Spain). Dr. Iglesias also worked as a post-doctoral researcher in the Center for Materials Processing and Tribology at Purdue University. Currently, she is an associate professor and the director of the new automotive engine specifications. Tribol Lubr Technol 62(9): 10-19 (2006)

[31] Spikes H. The history and mechanisms of ZDDP. Tribol Lett 17(3): 469-489 (2004)

[32] Espinosa T, Jiménez M, Sanes J, Jiménez A E, Iglesias M, Bermúdez M D. Ultra-low friction with a protic ionic liquid boundary film at the water-lubricated sapphire-stainless steel interface. Tribol Lett 53(1): 1-9 (2014)

[33] Iglesias M, Gonzalez-Olmos R, Cota I, Medina F. Brønsted ionic liquids: Study of physico-chemical properties and catalytic activity in aldol condensations. Chem Eng $J$ 162(2): 802-808 (2010)

[34] Qu J, Truhan J J. An efficient method for accurately determining wear volumes of sliders with non-flat wear scars and compound curvatures. Wear 261(7-8): 848-855 (2006)

[35] Cigno E, Magagnoli C, Pierce M S, Iglesias P. Lubricating ability of two phosphonium-based ionic liquids as additives of a bio-oil for use in wind turbines gearboxes. Wear 376-377: 756-765 (2017)

she is a Ph.D. candidate in the Tribology Laboratory of the Kate Gleason College of Engineering at Rochester Institute of Technology. Her current research focuses on investigation of environmentally friendly ionic liquids as lubricants or lubricant additives, sliding and rolling friction of materials, and lubrication and wear mechanism of different tribology systems.

Tribology Laboratory in the Kate Gleason College of Engineering at the Rochester Institute of Technology. Her research focuses on wear and friction of materials, ionic liquids as lubricants and additives of lubricants, bio-lubricants, nanostructured materials, and textured surfaces. Dr. Iglesias has extensive experience working on tribology and has published 35 peer-reviewed articles and more than 38 conference proceedings in the area. 